\title{
WILSON ALCIDEZ VALENZUELA PÉREZ. EL RACIONALISMO POLÍTICO EN JOHN LOCKE
}

Tunja: Universidad Pedagógica y Tecnológica de Colombia, 2008, pp. 280

\author{
Reseña de Hernán Martínez Ferro* \\ Profesor Escuela de Filosofía y Humanidades \\ Universidad Pedagógica y Tecnológica de Colombia
}

El libro del profesor Valenzuela es una investigación sistemática sobre el pensamiento político de uno de los padres del liberalismo: John Locke. Una investigación escrita en el estilo académico propio de una tesis doctoral, que por su rigurosidad, revisión de fuentes primarias, originalidad en la presentación de la temática, exhaustiva consulta de bibliografía en español e inglés y una envidiable claridad expositiva, le valió el reconocimiento del jurado de la Universidad Abat Oliba, de Barcelona-España, que le concedió el título de Doctor en Filosofía del Derecho con una calificación Cum Laude.

De entrada es importante destacar que siendo el pensamiento de John Locke tan decisivo en la configuración del mundo moderno, tanto en sus ideas epistemológicas como políticas, lo que ha suscitado numerosos y eruditos estudios en el mundo anglosajón - vale decir que en Estados Unidos se lo considera el teórico de la revolución de independencia-, ha sido menos estudiado en Hispanoamérica y muchísimo menos en nuestro País, en donde los trabajos especializados que han dado lugar a libros sobre Locke se pueden contar con los dedos de la mano. Mérito entonces de este libro del profesor Valenzuela que viene a llenar un vacío entre nosotros, invitándonos a repensar las ideas de tolerancia, límites y división del poder político, legitimidad del poder, concepto de Estado y soberanía, sociedad civil, relaciones iglesia-estado, democracia y libertad, derechos naturales, de resistencia y de propiedad; concepto e ideas que han configurado nuestro mundo político, que aún son objeto de discusión y hacen parte del lenguaje de

* Miembro del Grupo de Investigación: Filosofía, Sociedad y Educación.

Correo-e: hernan.martinez@uptc.edu.co 
reivindicaciones y movimientos sociales actuales, los cuales fueron pensados con agudeza por Locke.

En la amplia obra de Locke se pueden distinguir escritos de teoría del conocimiento y escritos políticos, siendo la relación entre ellos objeto de controversia entre los especialistas. Para algunos existe una estrecha vinculación entre los principios del conocimiento y los principios políticos, los cuales estarían fundamentados en el entendimiento de donde serían derivados demostrativamente. Lo que permitiría hablar de un mismo sistema. Para otros, en cambio, existe muy poca relación entre escritos sobre el conocimiento y los políticos: afirman que los escritos políticos obedecen a una justificación de la revolución de 1688 y constituyen un manifiesto de la clase emergente.

Frente a esa controversia, el profesor Valenzuela sostiene en su libro que el método de exposición utilizado por Locke en su teoría política es consecuencia de principios planteados en sus obra sobre el conocimiento, es decir que defiende la tesis del primer grupo, aunque reconoce que el pensamiento de Locke estuvo influenciado por las circunstancias políticas y sociales de la época. El situarse en esa postura obligó al profesor Valenzuela a ocuparse, en los siete capítulos del libro, tanto de escritos gnoseológicos como de escritos políticos y, lo que es más interesante, de la relación entre ellos.

La tesis del libro es: "demostrar que los temas centrales de la teoría política de John Locke, a saber: derecho a la tolerancia en materia de creencias y prácticas externas del culto a la divinidad; la ley moral y las bases de la sociedad; el estado de naturaleza como estado prepolítico regido por la ley de la razón; la distinción entre poder patriarcal, poder conyugal y poder político; la crítica a la monarquía absoluta jure divino; el origen contractual de la sociedad civil, y la fundamentación filosófica de la propiedad, pueden ser explicados y comprendidos a partir de la premisa según la cual, de la naturaleza racional del hombre derivan su natural derecho a la igualdad, a la libertad, a la vida y a las posesiones, para cuya salvaguarda los hombres entran en la sociedad política" (p. 15)

La tesis implica mostrar en los textos políticos de Locke dos asuntos: primero que el fundamento de la teoría política es la naturaleza racional del hombre y, en segundo lugar, que Locke pretendió, mediante el método deductivo inspirado en la axiomática de Euclides-Descartes, derivar los principios políticos en que se basa toda su teoría sobre la sociedad y el gobierno. 
Esto explica el título del libro, El Racionalismo político en John Locke, pues con la noción de "racionalismo" se hace referencia a los dos sentidos del término "razón": por una parte la característica distintiva y peculiar del hombre que hace de él un agente moral, es decir, un ser inteligente dotado de razón y reflexión, capaz de ley y, por tanto, sujeto de responsabilidad; pero, por otra parte, también a la razón como facultad discursiva mediante la cual la mente somete a juicio las proposiciones que se presentan a su consideración. Esta segunda acepción hace referencia, en Locke, al enfoque racionalista propuesto por Descartes en sus Meditaciones Metafísicas, esto es, un método demostrativo al estilo de la geometría, que parte de axioma (verdades autoevidentes) para, mediante demostraciones deductivas, derivar teoremas que son nuevas verdades del sistema. Método racionalista que pretende avanzar con evidencia, de una proposición a otra, haciendo de la claridad y la distinción los criterios de la verdad. Método que, según la tesis del profesor Valenzuela, aplica Locke a la moral y la política, las cuales no serían, como usualmente se cree, el campo de la incertidumbre, sino que podrían alcanzar, gracias al método, precisión y certidumbre. Ejemplo de ello, la proposición "no hay justicia donde no haya propiedad" se deduce de la definición de propiedad como derecho a algo, y de injustica como invasión en ese derecho; como señala Valenzuela citando a Locke: "esa proposición es tan verdadera como si fuera un teorema de Euclides".

Los argumentos a lo largo de todo el libro, en el que se van revisando los escritos políticos de Locke bajo la idea de mostrar que guardan una unidad metodológica de enfoque racionalista, son convincentes y nos terminan persuadiendo de que Locke persiguió como un sueño el ideal matemático de partir de principios claros y bien definidos como los axiomas geométricos para para deducir conclusiones claras y precisas. El que Locke hubiese cumplido con su sueño racionalista es en cambio algo con lo que el profesor Valenzuela no se compromete tanto. El punto de partida, el axioma "que los hombres nacen libres y dotados con la facultad de la razón", fue el fundamento que sirvió a Locke para plantear toda su teoría política. En la moral en cambio, como señala el profesor Valenzuela, Locke no escribió una ética demostrada según el modo geométrico. Locke consideraba que la razón había fallado en su gran empeño de demostrar la moral. Los razonamientos de los filósofos son largos y difíciles de comprender para la mayoría, siendo la discusión y la falta de claridad características que predominan.

Dejo, en esta corta reseña, temas y discusiones importantes de las que se ocupa el libro, como los análisis de los cuatro ensayos sobre la tolerancia, las relaciones 
entre el contractualismo de Locke y de Hobbes, la discusión con Strauss, el problema de la legitimidad del poder político, entre otros. Temas tratados con agudeza y precisión. Término recomendando la lectura de este libro inteligente y erudito, que cumple con lo que Ortega y Gasset llamó la cortesía del filósofo: la claridad. 